\title{
Hepatoprotective Effect of Aqueous Extract of Telfairia occidentalis on Cadmium Chloride-Induced Oxidative Stress and Hepatotoxicity in Rats
}

\author{
Johnson Olaleye Oladele ${ }^{1}$, Olu Israel Oyewole ${ }^{1, ~ *}$, Olamilekan Kabiru Bello², \\ Oluwaseun Titilope Oladele ${ }^{1}$ \\ ${ }^{1}$ Department of Biochemistry, Faculty of Basic and Applied Sciences, Osun State University, Osogbo, Nigeria \\ ${ }^{2}$ Department of Biochemistry, Faculty of Sciences, University of Ilorin, Ilorin, Nigeria
}

\author{
Email address: \\ ioluoye@yahoo.com (O. I. Oyewole) \\ ${ }^{*}$ Corresponding author
}

\section{To cite this article:}

Johnson Olaleye Oladele, Olu Israel Oyewole, Olamilekan Kabiru Bello, Oluwaseun Titilope Oladele. Hepatoprotective Effect of Aqueous Extract of Telfairia occidentalis on Cadmium Chloride-Induced Oxidative Stress and Hepatotoxicity in Rats. Journal of Drug Design and Medicinal Chemistry. Vol. 3, No. 3, 2017, pp. 32-36. doi: 10.11648/j.jddmc.20170303.11

Received: April 6, 2017; Accepted: June 5, 2017; Published: July 4, 2017

\begin{abstract}
Cadmium and its compounds have been classified as known human carcinogens. Telfairia occidentalis is a medicinal plant with a number of pharmacological activities attributed to its extracts. This study was designed to investigate the possible hepatoprotective effect of aqueous extract of Telfairia occidentalis on cadmium chloride $\left(\mathrm{CdCl}_{2}\right)$ induced oxidative stress and hepatotoxicity in experimental animals. Twenty-four (24) adult male rats were divided into 4 groups of 6 rats each. Group I received distilled water, group II, III, and IV were administered $5 \mathrm{mg} / \mathrm{kg}$ body weight $\mathrm{CdCl}_{2}$, group III, IV were treated with 200 and $400 \mathrm{mg} / \mathrm{kg}$ body weight (bw) respectively of aqueous extract of Telfairia occidentalis for 14 days. Results obtained showed that exposure of rats to cadmium induced hepatocellular injury as demonstrated by significant increased $(\mathrm{P}<0.05)$ in activities of Aspartate aminotransferase (AST), Alanine aminotransferase (ALT), Acid phosphatase $(\mathrm{ACP})$ and alkaline phosphatase (ALP). Lipid peroxidation was induced as shown by significant increase $(\mathrm{P}<0.05)$ in malondialdehyde (MDA) level and induction of oxidative stress with significant decrease $(\mathrm{P}<0.05)$ in reduced glutathione (GSH), Glutathione S-transferase (GST), Superoxide dismutase (SOD), Catalase (CAT) levels. Histological study of the liver shows loss of normal architecture, small-sized cytoplasmic vacuole, cellular degeneration and necrosis. However, concomitant administration of aqueous extract of Telfairia occidentalis with cadmium chloride attenuated the induced hepatic injury, lipid peroxidation, and oxidative stress. In conclusion, aqueous extract of Telfairia occidentalis offer hepatoprotection by scavenging free radicals, reversing/inhibiting oxidative stress pathways and protecting the structural integrity of the liver.
\end{abstract}

Keywords: Hepatotoxicity, Lipid Peroxidation, Oxidative Stress, Cadmium Chloride, Telfairia occidentalis

\section{Introduction}

Cadmium and its compounds have been classified as known human carcinogens. Epidemiological and mechanistic studies showed a relationship between exposure to cadmium and human cancers [1]. It has been suggested that ionic cadmium or compounds that release ionic cadmium causes genetic damage and carcinogenic species. Some studies on cultured mammalian cells have revealed that cadmium compounds induced genetic aberration which includes disruption of DNA repair processes, DNA strand breaks, gene mutations, cell transformation and chromosomal damage [1].

The acute hepatotoxicity of cadmium has been proposed to include direct toxic effect of the metal, ischemia due to endothelial cell damage and inflammation in which the kupffer cell activation and neutrophil infiltration perform a pivot function through a series of inflammatory mediators [2]. Arroyo, et al. [3] documented the mechanisms of Cadmium induced hepatotoxicity to include altering of calcium homeostasis leading to activation of protein kinase $\mathrm{C}$ (PKC) which drives the noxious effects of reactive oxygen 
species (ROS), aggravating oxidative stress and cellular damage resulting in apoptosis, inflammatory response generating infiltration and activation of phagocytic cells releasing more inflammatory mediators such as cytokine and ROS.

Cadmium induced hepatic damage is relatively associated oxidative stress. It binds to sulfhydryl groups with high affinity which in part provide protection by metallothionein (MT) and glutathione (GSH) because they are rich in cysteine residues [4]. The inability of thiols might also result into toxicity by altering the intracellular redox status, eliciting adverse effects on important biochemical processes. Cadmium induced lipid peroxidation and alter the prooxidant-antioxidant balance indirectly by damaging the antioxidant barrier. It decreases the level of non-enzymatic antioxidants such as glutathione (GSH), and inhibits the activities of antioxidant enzymes such as glutathione peroxidase (GPx), superoxide dismutase (SOD), catalase (CAT) and glutathione reductase (GR). Thus, $\mathrm{Cd}$ induces prooxidative state in cells via overproduction of ROS, superoxide anion $\left(\mathrm{O}_{2}\right)$, hydroxyl radical $\left(\mathrm{OH}^{-}\right)$and hydrogen peroxide $\left(\mathrm{H}_{2} \mathrm{O}_{2}\right)$.

Telfairia occidentalis is a medicinal plant with a number of pharmacological activities attributed to its extracts. Traditionally, it is used to boost blood in anemic patients and in the treatment of liver and high blood sugar problems [5, 6], convulsion [7], and reproductive and fertility issues [8]. Akubue et al., [9] reported its bioactive components to include oxalates, saponins, glycosides, flavonoids, alkaloids and resins. It is also found to contain blood enriching minerals such as iron, potassium, sodium, phosphorus, vitamins (thiamine, riboflavin, nicotinamide, ascorbic acid), and phytochemicals [10]. Nwanna and Oboh [11] established the antioxidant and hepatoprotective properties of polyphenol extracts from Telfairia occidentalis leaves on acetaminophen induced liver damage.

Base on this background, this study was designed to investigate the possible hepatoprotective effect of aqueous extract of Telfairia occidentalis on cadmium chloride induced oxidative stress and hepatotoxicity in experimental animals.

\section{Materials and Methods}

\subsection{Chemicals and Reagents}

Alanine aminotransferase

(ALT), Aspartate aminotransferase (AST), alkaline phosphatase (ALP) and Acid phosphatase (ACP) enzyme diagnostic kits are products of Randox Chemical Limited, England. All other chemicals were of analytical grade.

\subsection{Collection of Plant Material and Aqueous Extraction}

The fresh leaves of Telfairia occidentalis were purchased from vegetable section of Igbona market in Osogbo, Osun State. The leaves were thoroughly washed and blended, the paste was filtered to obtain a clear aqueous extract of the leaves. The sediment filtrate was air dried to obtain a powdery form which was used to prepare the $200 \mathrm{mg} / \mathrm{kg}$ and $400 \mathrm{mg} / \mathrm{kg}$ body weight used in this experiment.

\subsection{Experimental Animals}

Twenty-four male wistar albino rats weighing between $130-140 \mathrm{~g}$ were used for this experiment. The rats were obtained from Central Animal House, Osun State University Osogbo, Nigeria. The rats were kept in ventilated cage at optimum temperature and 12hours light / dark cycle and fed with commercial grower smash and water ad libitum. The experiment was carried out in accordance to current rules and guidelines that have been established for the care of the laboratory animals [12]. The rats were acclimatized for two weeks before treatment commenced.

\subsection{Experimental Design and Dose Regimen}

The twenty-four wistar albino rats were sorted into four (4) different groups containing six (6) rats each. The body weight and the average weight of each group were taken and recorded daily. Administration of aqueous extract of Telfairia occidentalis leaf (AETO) was done using the gavage method using oral canula. The animals were treated daily for 14 consecutive days. Group I received distilled water daily and serve as the Control, Group II received $5 \mathrm{mg} / \mathrm{kg}$ body weight $\mathrm{CdCl}_{2}$, Group III received $5 \mathrm{mg} / \mathrm{kg}$ body weight $\mathrm{CdCl}_{2}$ and $200 \mathrm{mg} / \mathrm{kg}$ body weight of AETO, Group IV received $5 \mathrm{mg} / \mathrm{kg}$ body weight $\mathrm{CdCl}_{2}$ and $400 \mathrm{mg} / \mathrm{kg}$ body weight of AETO.

\subsection{Sacrifice of Experimental Animals and Sample Collection}

The rats were weighed and sacrificed after $24 \mathrm{hrs}$ of last dose treatment under the influence of chloroform anesthesia. The livers were harvested immediately and stored on ice. Serum for biochemical analysis were obtained by collecting blood from the jugular vein into separate plain bottles, allowed to clot and centrifuged at $4000 \mathrm{rpm}$ for $30 \mathrm{mins}$. The serum obtained was stored in a refrigerator at $-4^{\circ} \mathrm{C}$ until it was used for biochemical analysis.

\subsection{Preparation of Homogenates}

The livers were rinsed with $\mathrm{KCl}$ and blotted with filter paper and weighed. They were then chopped into bits and homogenized in four volumes of the homogenizing buffer (0.1M Tris- $\mathrm{KCl}, \mathrm{pH} 7.4)$ using a Teflon homogenizer. The resulting homogenate was centrifuged at $12,500 \mathrm{~g}$ for 15 minutes in a cold centrifuge $\left(4^{\circ} \mathrm{C}\right)$, to obtain the post mitochondrial fraction. The supernatant was collected and used for biochemical analyses.

\subsection{Biochemical Assays}

Lipid peroxidation (malondialdehyde) was assessed by using the procedure of Vashney and Kale [13]. Superoxide dismutase (SOD) was assayed by the method of Misra and 
Fridovich [14]. Catalase activity was determined according to the method of Sinha, [15]. The method of Habig et al. [16] was used in the determination of Glutathione S-transferase (GST) activity. The level of reduced glutathione (GSH) in the liver samples was determined by the method described by Jollow et al [17]. Activities of alanine aminotransferase (ALT), aspartate aminotransferase (AST), alkaline phosphatase (ALP) and acid phosphatase (ACP) were measured in the serum of rats using the appropriate kits and method described by the manufacturer (Randox).

\subsection{Histological Examination}

The liver was immediately fixed in $10 \%$ formalin and embedded in paraffin wax. Fine sections (7-9 mm thickness) of the liver was then dewaxed in xylene, hydrated in decreasing percentage of alcohol and stained with hematoxylin and eosin. The stained sections were observed under a Leitz microscope and their photomicrograph taken at X 100 with a Canon (Meville, NY) Power Shot G2 Digital Camera.

\subsection{Statistical Analysis}

Data were expressed as mean \pm standard deviation (mean $\pm \mathrm{SD}$ ) and analyzed using one-way analysis of variance (ANOVA) with the aid of SPSS 12.0 computer software package (SPSS Inc; Chicago, U.S.A). Student's ttest was employed for comparison between two sets of data and differences at $\mathrm{P}<0.05$ were considered significant.

\section{Results}

Figure 1 and 2 shows the effect of Cadmium Chloride and aqueous leaf extract of Telfairia occidentalis on the antioxidant status of the experimental rats. Hepatic GSH, GST, SOD, and CAT were significantly reduced $(\mathrm{P}<0.05)$ as compared to the control, as well as significantly increase $(\mathrm{P}<0.05)$ in Lipid peroxidation (MDA) in rats treated with Cadmium chloride alone (group II). Administration of aqueous leaf extract of Telfairia occidentalis significantly $(\mathrm{P}<0.05)$ attenuate these anomalies in a dose dependent manner.

Figure 3 and 4 shows that rats exposed to $5 \mathrm{mg} / \mathrm{kg}$ body weight of Cadmium Chloride (group II) showed a significant increase $(\mathrm{P}<0.05)$ in serum concentration levels of ALT, AST, ACP and ALP as compared to the control (group I). These altered valves were reverted significantly $(\mathrm{P}<0.05)$ toward normal in a dose dependent manner in rats treated with 200 and $400 \mathrm{mg} / \mathrm{kg}$ body weight of aqueous leaf extract of Telfairia occidentalis (group III \& IV respectively).

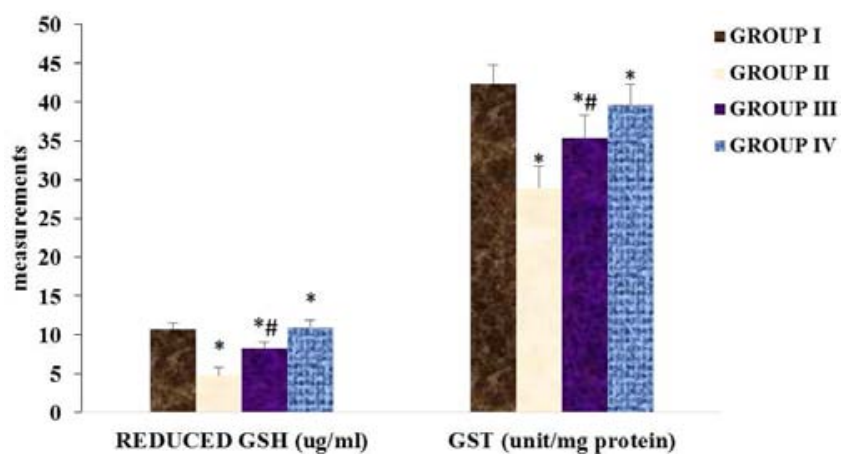

Figure 1. The effect of cadmium chloride and aqueous leaf extract of Telfairia occidentalis on reduced glutathione (GSH) and glutathione stransferase (GST).

Data presented as Mean \pm SD of 6 animals each per group. * Significantly different from normal control group at $\mathrm{P}<0.05$, " significantly different from group II at $\mathrm{P}<0.05$.

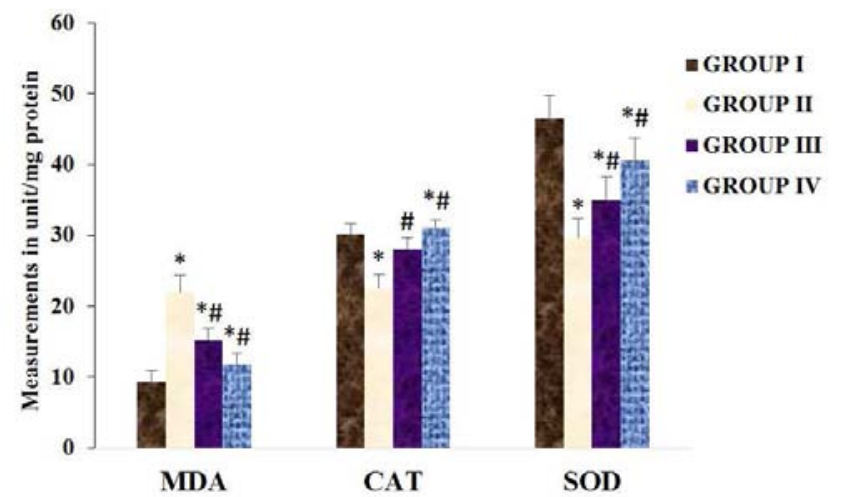

Figure 2. The effect of cadmium chloride and aqueous leaf extract of Telfairia occidentalis on lipid peroxidation (MDA) catalase (CAT) and superoxide dismutase (SOD).

Data presented as Mean \pm SD of 6 animals each per group. * Significantly different from normal control group at $\mathrm{P}<0.05$, " significantly different from group II at $\mathrm{P}<0.05$.

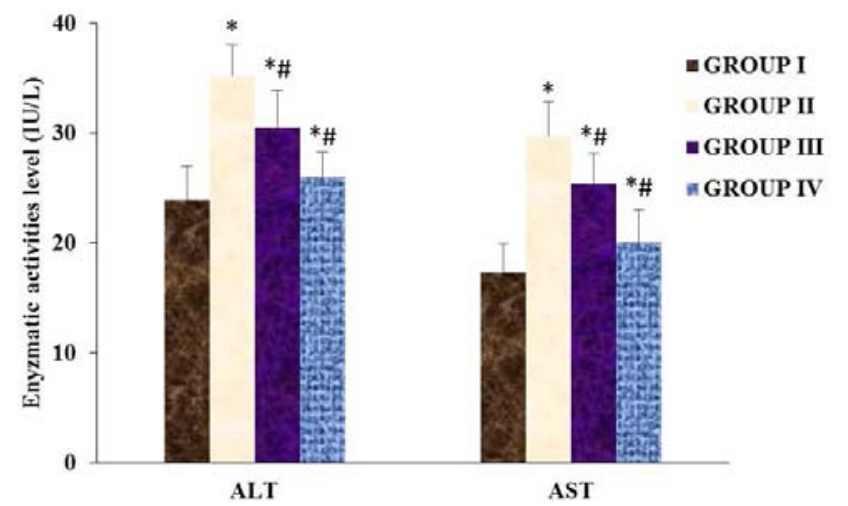

Figure 3. The effect of cadmium chloride and aqueous leaf extract of Telfairia occidentalis on alanine aminotransferase (ALT) and aspartate aminotransferase (AST).

Data presented as Mean \pm SD of 6 animals each per group. * Significantly different from normal control group at $\mathrm{P}<0.05$, ${ }^{\text {\# }}$ significantly different from group II at $\mathrm{P}<0.05$. 


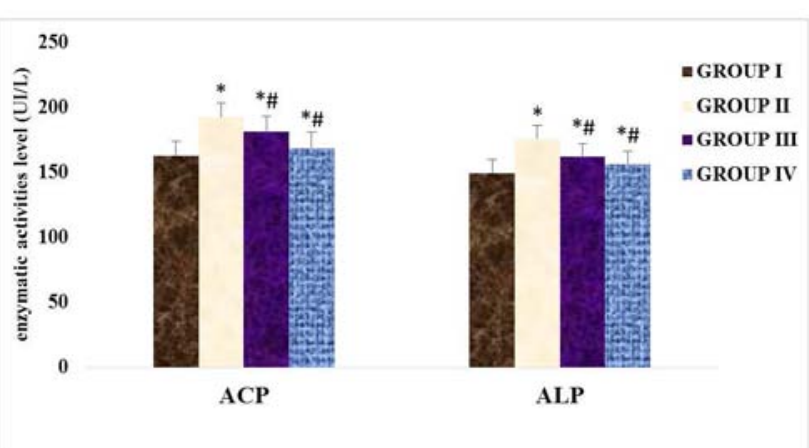

Figure 4. The effect of cadmium chloride and aqueous leaf extract of Telfairia occidentalis on alkaline phosphatase (ALP) and acid phosphatase (ACP).

Data presented as Mean \pm SD of 6 animals each per group. * Significantly different from normal control group at $\mathrm{P}<0.05$, ${ }^{\text { }}$ significantly different from group II at $\mathrm{P}<0.05$.

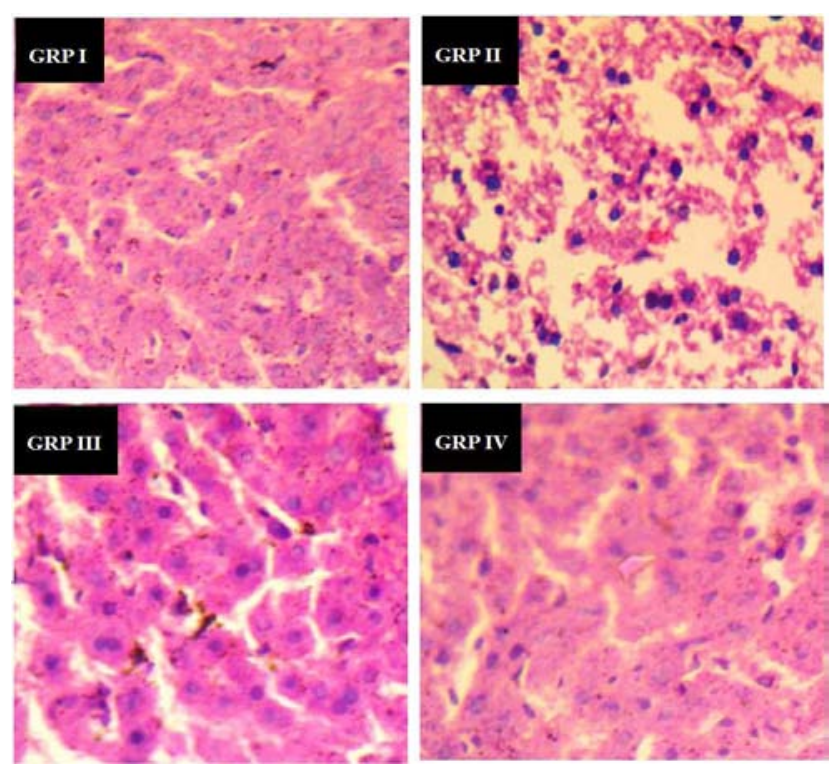

Figure 5. Representative $H \&$ E stained sections of liver of experimental rats $(\times 100)$.

Group I shows normal architecture structure and no visible lesion, group II shows loss of normal architecture, small-sized cytoplasmic vacuole, cellular degeneration and necrosis, group III shows mild visible lesion and group IV shows no visible lesion.

\section{Discussion}

Hepatotoxic effects of cadmium have been identified to be via direct toxic effects of the metals on cellular activities, exacerbating oxidative stress and cellular damage, inflammation and release of cytokine and ROS [3]. Having this in mind, this present study investigates the hepatoprotective effect of aqueous extract of Telfairia occidentalis on cadmium chloride induced oxidative stress and hepatotoxicity in wistar rats.

The results in figure 1 shows marked reduction in the level of reduced GSH and GST activity. This result agrees with the previous findings that cadmium decrease GST in the liver $[18,19]$. GSH is one of the major thiol-disulphide redox buffer in the cell and play fundamental role in the defense against free radical generation and oxidative damage. GST catalyses the reaction of conjugating xenobiotic with GSH to neutralized their electrophilic properties and facilitate their excretion. However, treatment with aqueous extract of Telfairia occidentalis significantly increase GSH content and GST activities. This indicates that the extract may enhance the biosynthesis of GSH or participated in the detoxification process of GST.

Similarly, exposure of experimental rats to cadmium chloride in this study resulted into oxidative stress as shown by the significant decreasing in SOD, CAT and significant increasing in lipid peroxidation (MDA) as compared to the control. This is tandem with the previous studies that showed that cadmium exposure causes increase in lipid peroxidation with decrease in activity of SOD and CAT [20, 21]. Administration of aqueous extract of Telfairia occidentalis significantly ameliorated the induced oxidative stress. This result suggested the antioxidant and free radical scavenging potentials of this extract.

Clinical assessment of hepatocellular injury and health status of liver is done routinely by measuring the activity level of Aspartate transaminase (AST) and Alanine transaminase (ALT). The result of this study revealed that there is a significant increase in serum AST and ALT level in rats treated with cadmium chloride alone as compared with control. Increase in serum AST and ALT levels may be as a result of metabolic changes in the liver, administration of xenobiotic, cirrhosis of the liver, hepatitis and liver cancer causing the leaking out of these enzymes from the liver to the blood system [22]. Administration of aqueous extract of Telfairia occidentalis significantly attenuates these adverse effects.

Acid phosphatase (ACP) and alkaline phosphatase (ALP) are marker enzymes for plasma membrane [23] and are required for proper functioning of organs [24]. ACP and ALP activities are significantly increased following the administration of cadmium chloride as compared with the control. This is an indication that the cadmium chloride elicits deleterious effects on the structural and functional integrity of cells which are dependent on a variety of phosphate esters for their vital processes [25]. However, treatment with aqueous extract of Telfairia occidentalis significantly reverse the activities of the enzymes in a dose dependent manner.

Result of the histological study of the liver shows loss of normal architecture, small-sized cytoplasmic vacuole, cellular degeneration and necrosis in the rats exposed to cadmium chloride alone, however, all these alterations were reversed following treatment with aqueous extract of Telfairia occidentalis. These histological findings further strengthen the biochemical results. This result is in tandem with the previous reports of [26] who documented that exposure of rats to cadmium causes some histopathological alterations such as cytoplasmic vacuolization, cellular degeneration and necrosis, loss of architecture of the parenchymatous tissue and severe glycogen depletion. 


\section{Conclusion}

In conclusion, the results of this present study shows that cadmium induced liver damage via oxidative stress with decrease in GSH, GST, SOD, CAT and increase in lipid peroxidation (MDA), compromising the structural integrity and function of liver membranes as shown by increased in serum AST, ALT, ACP, and ALP which is corroborated by histological studies. Taken together, aqueous extract of Telfairia occidentalis offer hepatoprotection by scavenging free radicals, reversing/inhibiting oxidative stress pathways and protecting the structural integrity of the liver membrane.

\section{Acknowledgement}

The authors are thankful to Dr. Olu Israel Oyewole for his support and technical assistance to conduct this study.

\section{References}

[1] IARC (1993) Beryllium Cadmium, Mercury, and exposures in the glass manufacturing industry. IARC Monographs on the Evaluation of Carcinogenic Risk of Chemicals to humans. Lyon, France: International Agency for Research on Cancer, Vol. 58, P. 444.

[2] Yamano T, DeCicco LA, Rikans LE (2000) Attenuation of cadmium- induced liver injury in senescent male fischer 344 rats: role of kupffer cells and inflammatory cytokines. Toxico Appl Pharmacol. 162: 68-75.

[3] Arroyo VS, Flores KM, Ortiz LB, Gomez-Quiroz LE, Gutierrez-Ruiz MC (2012) Liver and Cadmium toxicity. J. Drug Metabol Toxicol. S5: 001.

[4] Rikans LE, Yamano T (2000) Mechanisms of cadmiummediated acute hepatotoxicity. J. Biochem Mol Toxicol 14: 110-117.

[5] Eseyin OA, Igboasoiyi AC, Oforah E, Nkop N, Agboke A (2005) Hypoglycaemic activity of Telfairia occidentalis in rats. J. Pharmacol. Bioresour. 2: 36-42.

[6] Adaramoye OA, Achem J, Akintayo OO, Fafunso MA (2007) Hypolipidemic effect of Telfairia occidentalis (fluted pumpkin) in rats fed a cholesterol-rich diet. Journal of Medicinal Food. 10 (2): 330-336.

[7] Gbile ZO (1986) Ethnobotany, taxonomy and conservation of medicinal plants. In: Sofowora A, editor. The State of medicinal plants research in Nigeria. Ibadan: University of Ibadan Press, 13-29.

[8] Nwangwa EK, Mordi J, Ebeye OA, Ojieh AE (2007) Testicular regenerative effects induced by the extracts of Telfairia occidentalis in rats. Caderno de Pesquisa, série Biologia, 19: 27-35.

[9] Akubue PI, Kar A, Nnachetta FN (1980) Toxicity of extracts of roots and leaves of Telfairia occidentalis. Planta Med. 38: 339-343.

[10] Kayode AAA, kayode OT (2011) Some medicinal valves of Telfairia occidentalis: A review. American Journal of Biochemistry and Molecular biology. 1: 30-38.
[11] Nwanna EE, Oboh G (2007) Antioxidant and Hepatoprotective Properties of Polyphenol Extracts from Telfairia occidentalis (Fluted Pumpkin) Leaves on Acetaminophen Induced Liver Damage. Pakistan Journal of Biological Sciences. 10: 2682-2687.

[12] National Research Council (NRC) (2011) Guide for the care and use of laboratory animals 8th Edition. The National Academies Press.

[13] Varshney R, Kale RK (1990) Effect of calmodulin antagonists on radiation induced lipid peroxidation in microsomes. Int $\mathrm{J}$ Radiat Biol. 58: 733-743.

[14] Misra HP, Fridovich I (1972) The role of superoxide anion in the auto-oxidation of epinephrine and a simple assay for superoxide dismutase. J Biol Chem. 247: 3170-3175.

[15] Sinha AK (1972) Colorimetric assay of catalase. Analytical Biochemistry. 47: 389-394.

[16] Habig WA, Pabst MJ, Jacoby WB (1974) Glutathione transferases. The first enzymatic step in mercapturic acid formation. J. Biol. Chem. 249: 7130- 7139.

[17] Jollow DT, Mitchel JR, Zampaglione N, Gillete JR (1974) Bromobenzene induced liver necrosis: Protective role of glutathione and evidence of 3,4 bromobenzene oxide as hepatotoxic metabolites. Pharmacology. 11: 151-169.

[18] El-Demerdash FM, Yousef MI, Kedwany FS, Baghdadi HH (2004) Cadmium induced changes in lipid peroxidation, blood hematology, biochemical parameters and semen quality of male rats: protective role of vitamin $\mathrm{E}$ and $\mathrm{b}$-carotene. Food Chem. Toxicol. 42: 1563-1571.

[19] Renugaderi J, Prabu MS (2010) Cadmium induced hepatotoxicity in rats and the protective effects of naringenin. Exp. Toxicol Pathol. 62: 171-181.

[20] Newairy AA, El-Sharaky AS, Badreldeen MM, Eweda SM, Sheweita SA (2007) The heptatoprotective effects of selenium against Cadmium toxicity in rats. Toxicology 242: 23-30.

[21] Sinha M, Manna P, Sil PC. (2009) Induction of necrosis in Cadmium induced hepatic oxidative stress and its protection by the prophylactic properties of taurine. J. Trace Elem Med Biol. 23: 300-313.

[22] Chalasani N, Aljadhey H, Kesterson J, Murray MD, Hall SD (2004) Patients with elevated liver enzymes are not act high risk for statin hepatotoxicity. Gastroentero 126: $1287-1292$.

[23] Wright PJ, Plummer DT (1974) The use of urinary enzyme measurement to detect renal damage caused by nephritic compounds. Biochem Pharmacol. 23: 65-73.

[24] Brain RI, kay KO (1927) Kidney phosphatase II: The enzyme in disease. Biochem. J. 21: 1104-1103.

[25] Butterworth PJ, Moss DW (1966) Action of neuraminidase on human kidney alkaline phosphatase. Nature 209: 805-810.

[26] El-Sokkary GH, Nafady AA, Shabash EH (2010) Metatonin administration ameliorates Cadmium-induced oxidative stress and morphological changes in the liver of rats. Ecotoxicol. Environ Saf 73: 456-463. 